\title{
The Contour Electrode Array: Safety Study and Initial Patient Trials of a New Perimodiolar Design
}

\author{
*†Michael Tykocinski, *Elaine Saunders, *†Lawrence T. Cohen, \\ $* \ddagger$ Claudiu Treaba, †Robert J. S. Briggs, $\ddagger$ Peter Gibson, *†Graeme M. Clark, and \\ $* \leftarrow$ Robert S. C. Cowan
}

*Cooperative Research Centre for Cochlear Implant and Hearing Aid Innovation, Melbourne, tDepartment of Otolaryngology, University of Melbourne, Parkville, and \$Cochlear Limited, Lane Cove, Australia

Objective: The aim of these studies was to investigate the insertion properties and safety of a new intracochlear perimodiolar electrode array design (Contour).

Background: An electrode array positioned close to the neural elements could be expected to reduce stimulation thresholds and might potentially reduce channel interaction.

Methods: Two sequential studies were conducted. In study 1, the Contour electrode array was inserted in 12 human temporal bones. After cochlear surface preparation, the position of the array was noted and the basilar membrane was examined for insertion damage. On the basis of the outcome of this temporal bone study, study 2 investigated the Contour array, mounted on a Nucleus $\mathrm{CI}-24 \mathrm{M}$ device and implanted in three adult patients. Results: Study 1 showed that in 10 temporal bones, the Contour array was positioned close to the modiolus, and the basilar membrane was intact. In the two remaining bones, the arrays had pierced the basilar membrane and were positioned in the scala vestibuli apical to the penetration. Statistical analysis showed an equivalent probability of insertion-induced damage of the two array designs. In study 2 , image analysis indicated that the Contour electrodes were positioned closer to the modiolus than the standard Nucleus straight array. Lower $T$ and $C$ levels, but higher impedance values, were recorded from electrodes close to the modiolus. Initial speech perception data showed that all patients gained useful open-set speech perception, two patients achieving scores of $100 \%$ on sentence material 3 months postoperatively.

Conclusions: The temporal bone studies showed the Contour electrode array to be generally positioned closer to the modiolus than the standard Nucleus straight array, and to have an equivalent probability of causing insertion-induced damage. Key Words: Cochlear implant-Contour implant.

Otol Neurotol 22:33-41, 2001.
During the past decade, electrical stimulation of the auditory nerve using multichannel cochlear implants has become the treatment of choice for patients with bilateral profound sensorineural hearing loss. Several cochlear implant systems are in clinical use worldwide, all of which aim to stimulate the spiral ganglion cells and their dendrites using multichannel electrode arrays inserted into the scala tympani. One differential feature of these implant systems is the design of the electrode array. The Nucleus $\mathrm{Cl}-22$ and $\mathrm{Cl}-24$ implant systems (Cochlear Ltd., Sydney, Australia) both incorporate a tapered, straight electrode array featuring 22 platinum (Pt) fullband stimulating electrodes on a silicone rubber carrier.

Supported by the Cooperative Research Centre for Cochlear Implant and Hearing Aid Innovation, an initiative of the Department of Industry, Trade and Tourism of the Commonwealth of Australia, and by Cochlear Limited.

Address correspondence and reprint requests to Dr. Michael Tykocinski, CRC for Cochlear Implant \& Hearing Aid Innovation, 384 Albert Street, East Melbourne, ViC 3002, Australia.
When implanted, the electrode array lies along the outer wall of the scala tympani (1-3). However, animal experiments and computer modeling studies have indicated that the preferable position of an electrode array is close to the modiolus. A perimodiolar position of the electrode array could be expected to result in reduced stimulus thresholds and stimulating currents, an increased dynamic range, and more localized stimulation of the neural elements (4-6).

The development of perimodiolar electrode arrays, which are easy and safe to implant, has been technically challenging. It is essential to prevent damage to sensitive cochlear structures, such as the basilar membrane or the osseous spiral lamina, to avoid the loss of existing spiral ganglion cells $(7-10)$. The electrode should also be designed to allow atraumatic explantation if reinsertion should be required because of implant failure. Published insertion study data on prototype perimodiolar arrays often demonstrate significant flaws in the experimental array, primarily caused by insertion-induced damage of the intracochlear structures $(3,11,12)$. 
The Contour electrode (Cochlear Limited, Lane Cove, Australia) is an intracochlear perimodiolar electrode array design developed by Cochlear Limited and the Cooperative Research Centre for Cochlear Implant and Hearing Aid Innovation and with surgical feedback from cochlear implant centers at the Universitäts-HNO-Klinik in Freiburg, Germany, and the New York University Medical Center, U.S.A. The silicone elastomer carrier is precurved and tapers from a tip diameter of $0.5 \mathrm{~mm}$ to $0.8 \mathrm{~mm}$ at the proximal end of the electrode array. The degree of curvature was calculated from systematic analysis of Silastic molds of adult temporal bones (13). A Pt stylet inserted into a lumen in the array's silicone carrier holds the electrode straight before insertion (Fig. 1 A). The stylet is malleable at the tip to allow the array to curve during insertion. Withdrawal of the stylet during and/or after insertion allows the array to take up its final curved perimodiolar shape (Fig. 1 B). The Contour electrode array has $22 \mathrm{Pt}$ half-band electrodes embedded along the initial $15.5 \mathrm{~mm}$ of the silicone carrier. The $\mathrm{Pt}$ electrodes are positioned on the modiolar side of the electrode array (Fig. 1), resulting in an electrode carrier with a smooth lateral surface. Each electrode has a width of $0.3 \mathrm{~mm}$ and a geometric area of $0.28 \mathrm{~mm}^{2}$ to 0.31 $\mathrm{mm}^{2}$. This compares with an average geometric area of $0.48 \mathrm{~mm}^{2}$ for a full-band electrode on the Nucleus standard straight array. The array has a silicone marker rib, proximal to the Pt electrodes, at $22 \mathrm{~mm}$ as a guide to depth of insertion for the surgeon.

\section{AIMS AND ORGANIZATION}

This article reports the results of sequential studies (Fig. 2) investigating the insertion properties and safety of a new intracochlear electrode array (Contour) in human cadaver temporal bones and subsequently in a limited patient trial. The outcomes of the temporal bone insertions were statistically analyzed to assess the probability of damage to the basilar membrane in comparison with that reported by Shepherd et al. (1) for the prototype

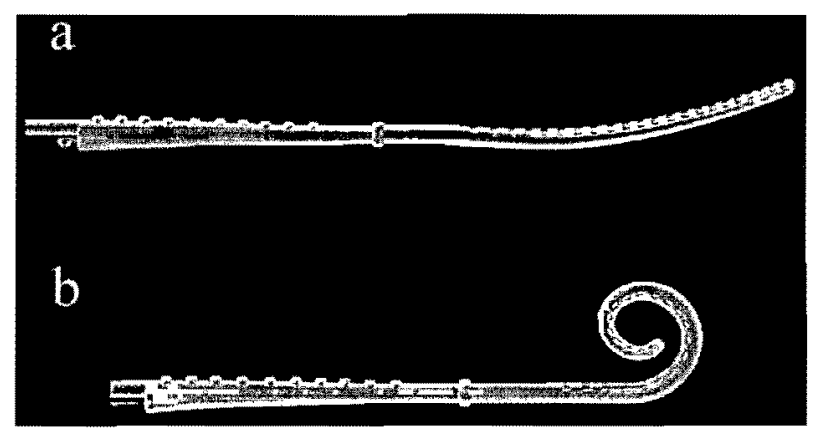

FIG. 1. The Contour electrode array with 22 half-band platinum (Pt) electrodes on the modiolar side of the silicone elastomer carrier. A: With the stylet in place, the electrode array is held nearly straight, while it recoils into a perimodiolar shape after the stylet has been withdrawn (B). The marker rib proximal to the $\mathrm{Pt}$ electrodes is clearly visible. Each electrode has a width of 0.3 $\mathrm{mm}$.

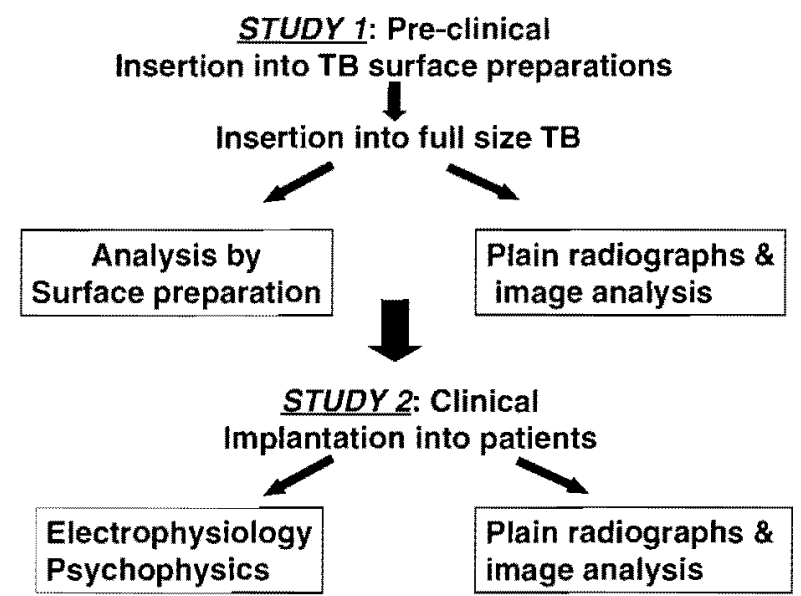

FIG. 2. Succession of the reported studies. The limited clinical trial was begun only after the preclinical trial had been successfully completed.

Nucleus straight electrode array. Although the analysis techniques used in our study were different from those used by Shepherd et al, it is the most appropriate available benchmark study for comparison. On the basis of the results of the temporal bone studies, a limited trial in adult cochlear implant patients (study 2) was initiated, using the surgical procedures developed from study 1. These studies were conducted as part of a multicenter investigation with New York University Medical Center and the Universitäts-HNO-Klinik in Freiburg. This article presents the results from the Melbourne study only.

To facilitate the clear presentation of the methodology and results, and to reinforce the sequential process of the two studies, the methods and results are presented together sequentially for each study, followed by a general discussion of the outcomes. Preliminary results of the current study have been presented earlier (14).

\section{STUDY 1: TEMPORAL BONE INSERTIONS}

\section{Methods}

Twelve formalinized human temporal bones from cadavers of unknown gender were implanted with pristine Contour electrode arrays. Two surgeons, experienced with both standard and experimental electrode arrays, performed six insertions each. The entire procedure was videotaped for each temporal bone, and still photographs were taken for documentation. Feedback was not provided to the surgeon during the insertion procedure.

Preliminary insertion experiments using the same electrode design on surface preparations of human cochleae had been carried out previously. The results showed that both a cochleostomy of $1.5 \mathrm{~mm}$ to $2 \mathrm{~mm}$ diameter, inferior and slightly anterior to the round window, as well as a partial withdrawal of the stylet whenever resistance was experienced, facilitated an optimal electrode insertion. These findings determined the protocol for both the cochleostomy and the insertion technique in study 1 . The temporal bones were prepared as 
for cochlear implant surgery: a cortical mastoidectomy and a posterior tympanotomy were performed to access the mesotympanon and the promontory. A cochleostomy of $1.5 \mathrm{~mm}$ to $2.0 \mathrm{~mm}$ was drilled inferior to, slightly anterior to, and including the round window. This diameter is slightly larger than that used in clinical practice in Melbourne for the standard straight Nucleus array. When the round window membrane was reflected superiorly, the lower basal turn of the scala tympani was well visualized, as was the undersurface of the basilar membrane and the modiolar wall. After lubrication, effected by placing a small amount of lubricant ( $40 \%$ glycerin/water) into the cochleostomy, and orientation of the electrodes toward the modiolus, the array was inserted with the stylet in place. If resistance was felt, the stylet was partially $(1-2 \mathrm{~mm})$ withdrawn, allowing further insertion of the electrode array. This partial removal of the stylet was repeated if resistance was experienced again. This stepwise procedure was used in the majority of temporal bones. However, in two cases, a slightly different procedure of advancing the electrode array while holding the stylet stationary was performed after initial resistance was encountered. All electrodes were fully inserted, with the marker rib at the level of the round window, without any need to forcibly overcome resistance.

After insertion, the electrode array was fixed in its position by histoacrylic glue. A cochlear surface preparation was then performed. After the removal of the endosteum of the scala vestibuli, the underlying basilar membrane was inspected under the operating microscope for tears or penetration by the electrode array. Subsequently, image analysis (2) was performed on Cochlear view radiographs (15) taken from each of the implanted temporal bones (Fig. 3), whereby the lateral positions of the electrode bands were estimated relative to mean outer and inner wall functions obtained from 11 Silastic molds of the scala tympani and scaled to fit the size of the actual cochlea (3). By use of this method, which has been described previously in detail $(2,3)$, it is possible to esti- mate both the position of each electrode band and that of the modiolar wall of the cochlea.

\section{RESULTS}

After the surface preparation, all 12 Contour electrode arrays were seen to have been initially inserted into the scala tympani. The mean insertion depth was $410.9^{\circ} \pm$ 39.4 SD, which is deeper than the usual insertion depth of the standard straight array $\left(351.8^{\circ} \pm 62.6 \mathrm{SD}\right.$; based on unpublished data from 23 female patients who received a Nucleus CI-22 or CI-24 implant with the standard straight array; L. Cohen, personal communication). Of the 12 insertions, the Contour electrode array was seen to be within the scala tympani for its entire length in 10 of the temporal bones. No insertion-induced damage to the basilar membrane was visible on examination with the operating microscope in any of these specimens, and the electrode array was seen to be positioned close to the modiolus, as shown in the representative example in Figures $4 \mathrm{~A}$ and $5 \mathrm{~B}$.

In the two remaining temporal bones, the electrode array penetrated the basilar membrane at $\sim 170^{\circ}$, as shown in Figure 4 B. The perforations occurred laterally, close to the junction of the basilar membrane with the spiral ligament. In both cases, the distal part of the electrode array rested on top of the basilar membrane, without causing further visible trauma to either the basilar membrane or the osseous spiral lamina. Whereas both arrays showed a position close to the modiolus within the lower basal turn and toward the electrode tip, they were positioned close to the outer wall of the scala tympani at the area of penetration of the basilar membrane (Fig. 5 C). The osseous spiral lamina appeared intact in the region where the electrode pierced the basilar membrane, and it appeared to prevent the electrode array from taking up a perimodiolar position in this region. It should be noted that the surgical procedure had been modified in one of these bones in that, rather than the stylet being withdrawn and then the electrode advanced, the array

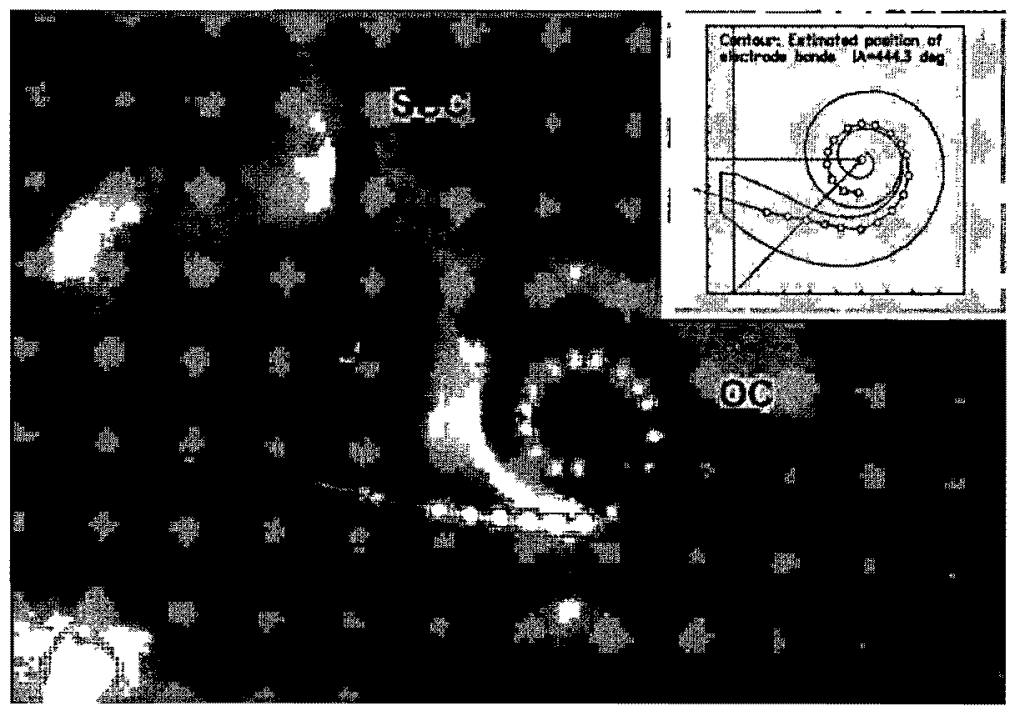

FIG. 3. Cochlear view radiograph of temporal bone (TB) 2 after insertion with a Contour electrode array. The landmarks for orientation (SSC, superior semicircular canal; $V$, vestibule; OC, otic capsule) are clearly visible. The inset shows the image analysis reconstruction of the same temporal bone. The frame shows the mean position of the outer and inner walls of the scala tympani (solid lines) scaled to fit the size of the cochlea in the original radiograph, the approximate position of the round window, and the estimated positions of the electrode bands of the Contour electrode array (white circles). The insertion angle (|A) of the most apical electrode band is given. 

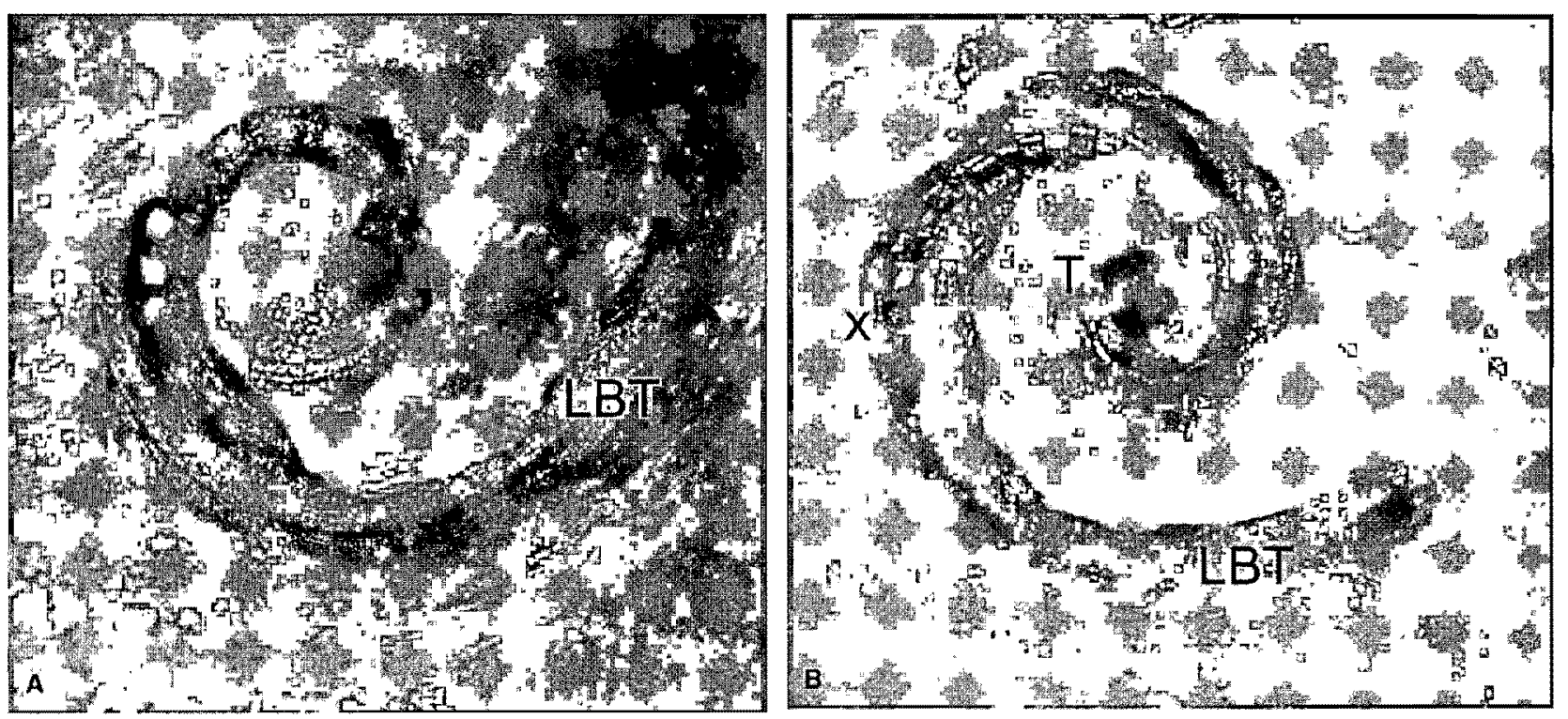

FIG. 4. Photomicrographs of two temporal bone surface preparations after implantation of the Contour electrode array. The roof of the scala vestibuli has been removed, and the upper surface of the basilar membrane is visible. A: Temporal bone 2: an atraumatic insertion of the Contour array into the scala tympani. The electrodes are clearly visible under the intact basilar membrane. Note the perimodiolar position of the electrode array. B: Temporal bone 7: the electrode array perforated the basilar membrane $(x)$ close to the outer wall of the otic capsule and is positioned on top of the basilar membrane for the remainder of its length. Each electrode band has a width of $0.3 \mathrm{~mm}$. LBT, lower basal turn; $T$, electrode tip.

had been pushed forward off the stylet after resistance was initially encountered.

The surgeons perceived the Contour electrode array as somewhat stiffer and more bulky than the standard straight array. However, the insertion of the array itself into the cochlea was smoother in comparison with the standard straight array. It was found that care was required during insertion to ensure that the electrodes were orientated toward the modiolus. In addition, the surgeon needed both hands to steady and advance the electrode and then to remove the stylet.

\section{Statistical analysis}

To compare the probability of insertion-induced damage from the Contour electrode array with that from the standard straight array, the results of study 1 were compared with an initial insertion study of prototype Nucleus straight arrays. This study reported perforations to have occurred in 1 of 9 temporal bones studied and basilar membrane damage in 2 others (1). However, methodologic differences between these studies may limit the generality of the statistical comparison. Shepherd et al. (1) used only fresh (i.e., $<24$ hours old) temporal bones, all from male donors without otologic disease. In the current study, the temporal bones had been preserved in formalin, and the medical histories and genders of their donors were unknown. In the current study, a lubricant was used to facilitate implantation because the bones had been preserved. All insertions by Shepherd at al. (1) were conducted through the round window, and two different
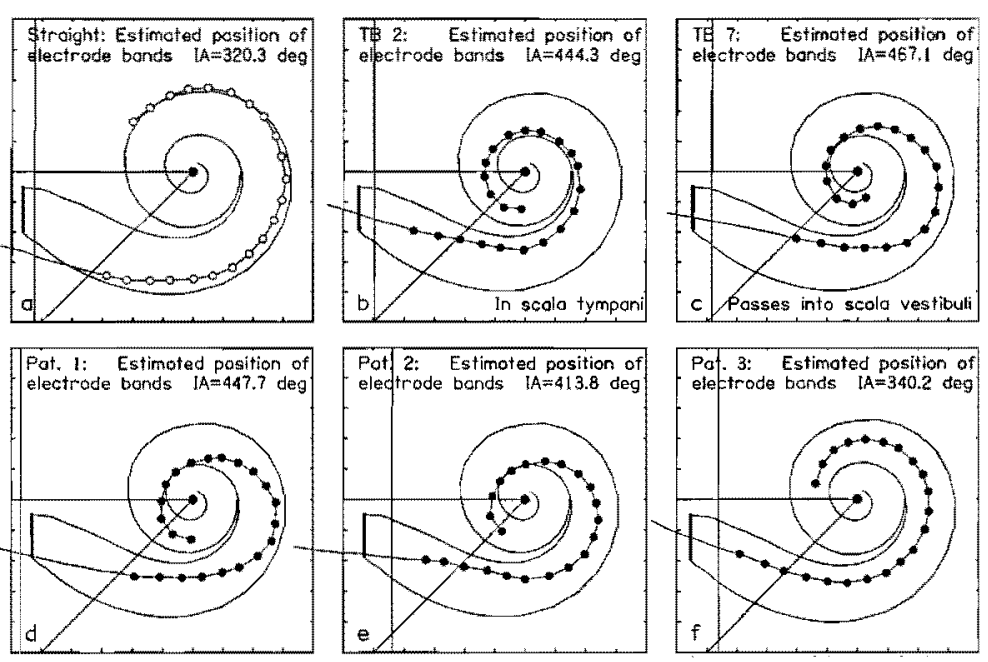

FIG. 5. Image analysis of Cochlear view radiographs. A: Standard straight Nucleus array in a representative patient for comparison. B-F: Estimated position of each electrode band on the Contour electrode array in two representative temporal bones $(\mathrm{B}, \mathrm{C})$ and in all three implanted patients (D$F$ ). Note the insertion angle (IA) of the most apical electrode band, which is indicaled in each frame. 
prototype electrode array designs, tapered and stepped, were assessed. However, because no significant differences were reported for these electrode array designs, the results were treated as a single sample for statistical comparison with those from the current study.

The $\chi^{2}$ and the Fisher exact tests were used to statistically describe the difference between the expected and the observed frequencies of events. In addition, the binominal distributions, expressing the $95 \%$ confidence interval for the probability of damage in both studies, were calculated and compared. As shown in Table 1, the $95 \%$ confidence intervals on the estimate of the probability of damage from the studies of Shepherd et al. (1) and the present study 1 are overlapping. When the results of both studies were compared with each other using the $\chi^{2}(p=$ $0.7871)$ and the Fisher exact test $(p=1.0000)$, no significant difference in the damage ratio between both studies was found. This suggests that the probability of damage in both studies is equivalent, although the low power of these tests because of the small sample size must be noted.

\section{STUDY 2: LIMITED PATIENT TRIAL}

\section{Methods}

After analysis of the results from the temporal bone study, approval was gained from the Human Research Ethics Committee of the Royal Victorian Eye and Ear Hospital to proceed with a limited trial with adult patients. The candidates were thoroughly informed about both the standard surgical procedure and the nature and perceived risks of the experimental Contour electrode array before consent was sought and given. Three patients underwent implantation with the Contour electrode array mounted on a Nucleus CI-24M implant. The patients were female and had become deaf postlinguistically. The origin of their hearing loss was most likely hereditary in each case, with progressive deterioration of hearing (Table 2).

The standard approach for cochlear implant surgery in Melbourne was used. A cortical mastoidectomy was performed, and the sinodural angle was drilled out wide enough to accommodate the receiver-stimulator. The facial recess was opened, and the promontory and the round window niche were visualized. The cochleostomy

TABLE 1. Damage ratio and $95 \%$ confidence interval on probability of penetration of the basilar membrane by the electrode array in insertion studies of human temporal bones for the Contour electrode array (study I) and prototype Nucleus straight electrode array (reference 1)

95\% Confidence

\begin{tabular}{cccc} 
Study & Electrode array & $\begin{array}{c}\text { Damage } \\
\text { ratio }\end{array}$ & $\begin{array}{c}95 \% \text { Confidence } \\
\text { interval (probability } \\
\text { of damage) }\end{array}$ \\
\hline $\begin{array}{c}\text { Current study 1 } \\
\begin{array}{c}\text { Shepherd et al. } \\
\text { (reference 1) }\end{array}\end{array}$ & $\begin{array}{c}\text { Prototype Nucleus } \\
\text { straight }\end{array}$ & $\begin{array}{l}2 / 12 \\
1 / 9\end{array}$ & 0.02 to 0.47 \\
\hline
\end{tabular}

TABLE 2. Patient details, preoperative speech perception scores using hearing aids, and postoperative speech perception scores for three adult patients using the Nucleus SPrint speech processor with the Contour electrode array (study 2), recorded at 3 or 6 months postoperatively

\begin{tabular}{ccccc}
\hline $\begin{array}{c}\text { Patient } \\
\text { no. }\end{array}$ & $\begin{array}{c}\text { Age } \\
\text { (yrs) }\end{array}$ & $\begin{array}{c}\text { Years profound } \\
\text { deafness }\end{array}$ & $\begin{array}{c}\text { Preoperative } \\
\text { speech scores* }\end{array}$ & $\begin{array}{r}\text { Postoperative } \\
\text { speech scores }\end{array}$ \\
\hline 1 & 65 & 4 & 42 & $70 \dagger$ \\
2 & 28 & 5 & 32 & $97 \dagger$ \\
3 & 55 & 2.5 & 34 & $100 \%$ \\
\hline
\end{tabular}

*Preoperative scores are for the implanted ear, aided.

\$6-month assessment.

$\$ 3$-month assessment.

Speech perception scores are percentage scores on open-set CID sentences presented in quiet.

was drilled as outlined in study 1 . Hyaluronic acid (Healon), a standard surgical lubricant, was injected into the basal turn, both for lubrication and to prevent bone dust or blood from entering the cochlea. After orientation of the electrodes toward the modiolus, the array was inserted. Resistance was encountered in each patient during the insertion, and the stylet was partially withdrawn for $-1 \mathrm{~mm}$ to $2 \mathrm{~mm}$ before the electrode was inserted farther. After full insertion, the stylet was then withdrawn completely, the cochleostomy was sealed with fibrous tissue, the receiver/stimulator was fastened in its bed with a nylon tie, and the wound was closed. Impedance testing of all electrodes was performed at the completion of surgery, and a Cochlear view radiograph (15) was taken within 1 week of surgery for image analysis. A medical review was performed and the impedance test was repeated -1 week after surgery. Two weeks after surgery, the initial mapping took place according to our standard procedures, using a pulse width of $25 \mu \mathrm{s}$ and an interpulse gap of $45 \mu$ s. Impedance was measured before and after the initial electrical stimulation.

The preliminary electrophysiologic and psychophysical data of the three patients were compared with data obtained from a control group of seven female adult cochlear implant users (mean age 46.1 year $\pm 20.0 \mathrm{SD}$ ). These control patients had previously undergone implantation with the CI-24M implant with the standard straight array and were selected at random from the Melbourne clinical population. All impedance data were recorded in common ground mode.

\section{Results}

The surgical implantation proceeded without complications in all patients. Consistently with the temporal bone studies, the insertion of the Contour array into the scala tympani was easier in comparison with the standard straight array. However, the removal of the stylet and the need for careful orientation of the electrodes toward the modiolus made the surgery more complex than that for the standard straight array. All three Contour arrays were fully inserted, with the marker rib at the level of the cochleostomy. Impedance testing immediately after surgery demonstrated that all electrodes were functional, 
and postoperative recovery was uneventful in all patients.

\section{Image analysis}

The postoperative radiograph and subsequent image analysis (Fig. 5 D,E) showed that the Contour electrode array was inserted deeply in patients $I$ and $2\left(447.7^{\circ}\right.$ and $413.8^{\circ}$ ). In patient 1 (Fig. $5 \mathrm{D}$ ), the electrode array was positioned close to the modiolus in the lower basal turn and at the tip, but more laterally at the first bend (electrodes 5-13). In patient 2 (Fig. $5 \mathrm{E}$ ), the electrode was positioned close to the modiolus in the lower basal turn and the region of the electrode tip, and approximately half way between the outer wall of the scala tympani and the modiolus around the first bend (electrodes 7-13). The array of patient 3 (Fig. $5 \mathrm{~F}$ ) was positioned at a more uniform distance from the modiolus. It was a full, but less deep insertion of $340.2^{\circ}$.

\section{Impedance}

Intraoperatively, the impedances recorded for the Contour patients in common ground mode varied between $4.03 \mathrm{kOhm}$ and $11.5 \mathrm{kOhm}$ (Fig. $6 \mathrm{~A}-\mathrm{C}$ ). The impedances were generally increased 2 weeks after surgery. However, after initial electrical stimulation on electrodes 3 through 22, the impedances dropped across all stimulated electrodes (Fig. $6 \mathrm{~A}-\mathrm{C}$ ).

For an electrode in an infinite fluid medium, impedance is approximately inversely proportional to the geo- metric surface area of the electrode. To eliminate the influence of surface area, the impedance data were normalized to the area of the most basal electrode on the standard straight electrode array. This also enabled us to compare the impedances of these patients with those of the control group, who underwent implantation with the standard straight array. The area-corrected impedance data from the Contour patients suggested a negative correlation of impedance with the estimated radial distance of the Contour electrode array from the modiolus (Fig. 6 D-F).

The mean impedances measured in common ground of the control group $(n=7)$, who underwent implantation with the standard straight array, showed only moderate variations across electrodes (Fig. 7 A). The impedances ranged between $1.66 \mathrm{kOhm}$ and $3.36 \mathrm{kOhm}$ when measured intraoperatively. After 1 week, an increase in impedance across all electrodes was observed, with values recorded between $3.05 \mathrm{kOhm}$ and $6.86 \mathrm{kOhm}$. A further rise was observed 2 weeks after surgery. After initial electrical stimulation on electrodes 3 through 22 , a small decrease on all stimulated electrodes was observed. Generally, the impedances increased from the basal to the apical electrodes (Fig. 7 A). In order to determine whether this increase was predominantly caused by the decrease in electrode area, from the basal to the most apical electrodes, impedances were normalized to the area of the most basal electrode on the array. The area-corrected impedances for the standard straight array were essen-

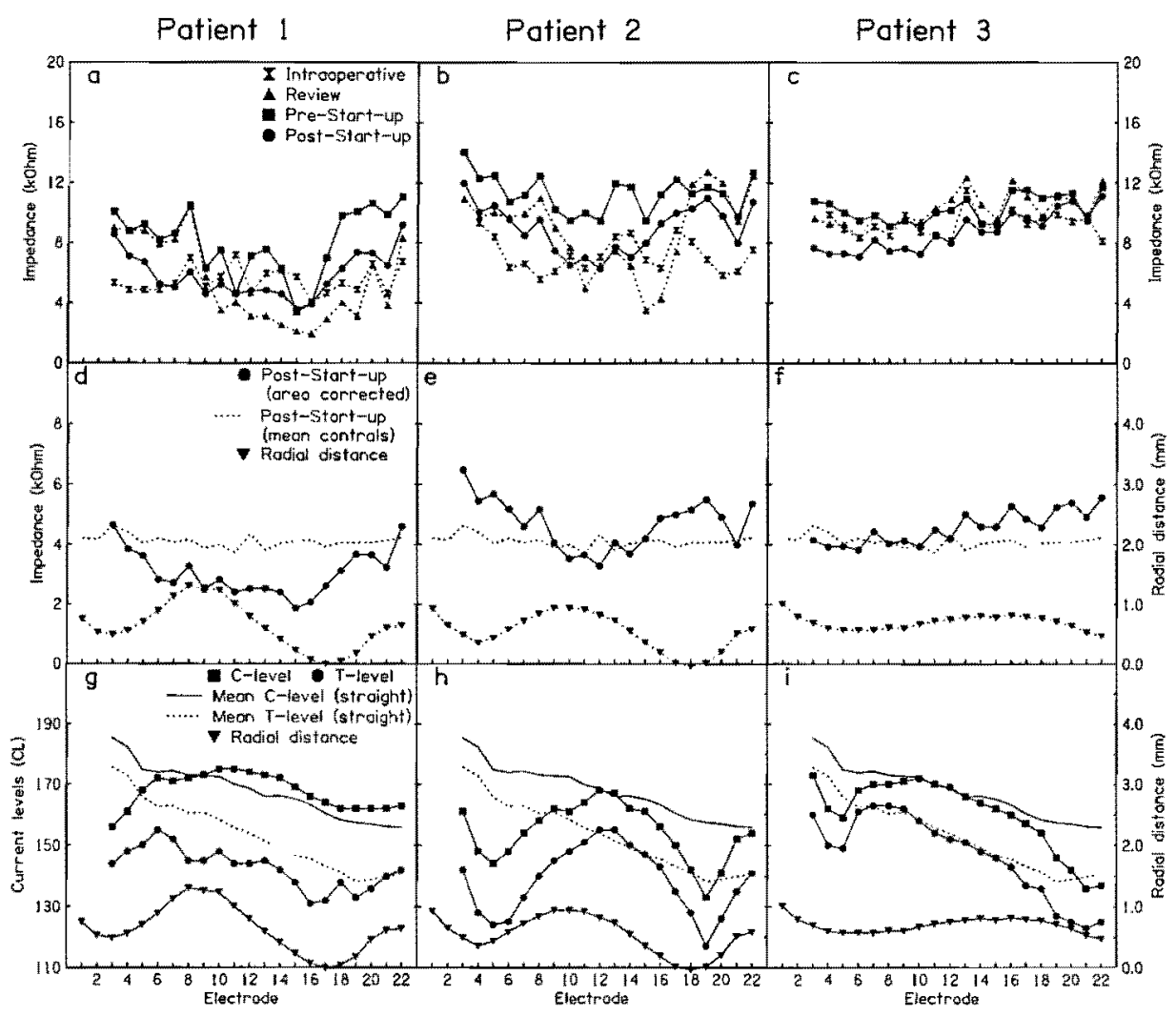

FIG. 6. Impedances measured in common ground mode $(\mathbf{A}-\mathbf{F})$ and current levels $(\mathbf{G}-1)$ of all patients who underwent implantation with the Contour electrode array, D-I: Estimated radial distance of the electrodes from the modiolus. A-C: Original impedance data during the first 2 weeks after cochlear implantation. D-F: Areacorrected impedances after the initial stimulation of electrodes 3222 weeks after surgery. Broken line, mean area-corrected impedances of the control group $(n=7)$, who underwent implantation with the standard straight electrode array. G-I: $T$ and $C$ levels at the time of initial electrical stimulation. For comparison, the $\mathrm{T}$ and $\mathrm{C}$ levels of the control group are also given (solid and broken lines). 


\section{Control group}

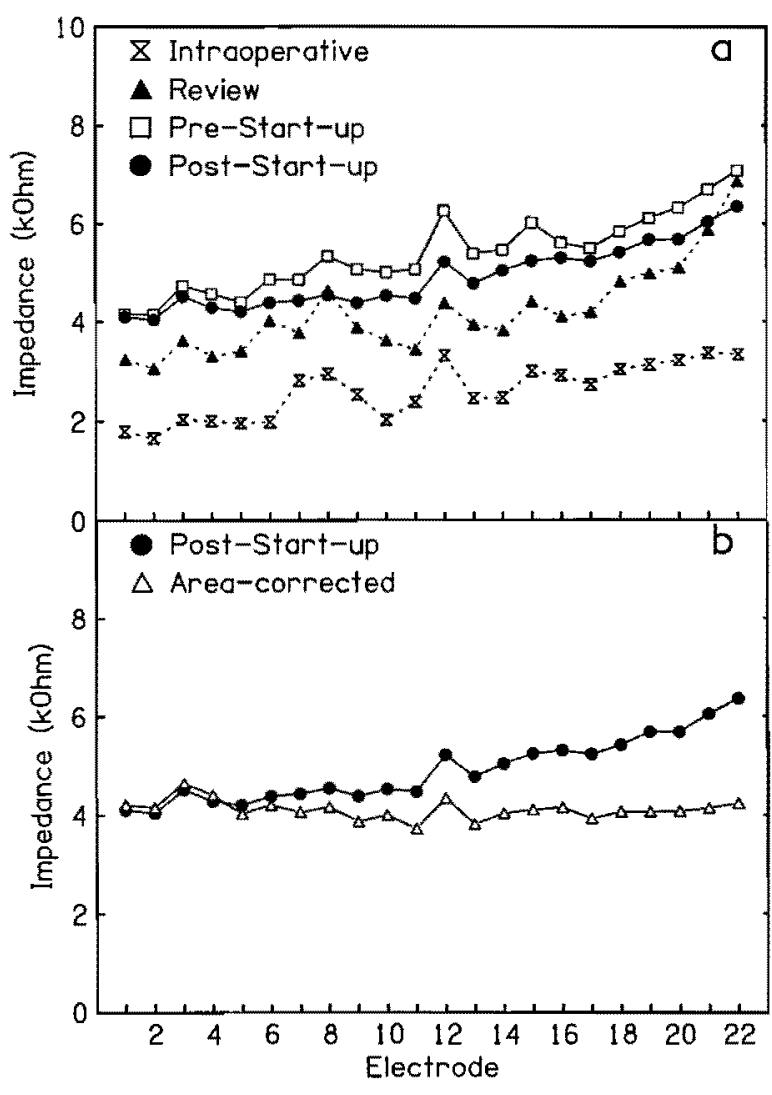

FIG. 7. Impedance data of the control group, comprising seven female patients who underwent implantation with the Nucleus $\mathrm{Cl}-24 \mathrm{M}$ with a standard straight electrode array. A: Original impedances monitored in common ground mode intraoperatively and 1 and 2 weeks after surgery. B: Original impedances after the initial electrical stimulation 2 weeks after surgery, and the same data corrected for the difference in surface area between the electrodes along the array.

tially constant across all electrodes (Fig. 7 B). This suggests that the variation in surface area of the electrodes along the array is the dominant factor responsible for the observed differences in impedance in the control group.

\section{Thresholds and comfortable levels}

For the Contour patients, the threshold (T) and comfortable (C) levels were determined for electrodes 3 to 22 in monopolar mode during the mapping session, 2 weeks postoperatively. The $\mathrm{T}$ levels ranged between 117 and 163 current levels (CL), and the $C$ levels ranged between 133 and $168 \mathrm{CL}$ for all three patients, respectively (Fig. $6 \mathrm{G}-\mathrm{I})$. In particular, in patients 1 and 2 , the $T$ and $C$ levels appeared to vary inversely with the estimated radial distance of the electrode from the modiolus (Fig. 6 G-I).

Individual $\mathrm{T}$ and $\mathrm{C}$ levels measured in the control group varied widely between subjects: $T$ levels were between $115 \mathrm{CL}$ and $191 \mathrm{CL}$, and $\mathrm{C}$ levels ranged between $132 \mathrm{CL}$ and $206 \mathrm{CL}$. The mean values for $\mathrm{T}$ and $\mathrm{C}$ levels progressively decreased from the basal to the tip electrodes, whereas the dynamic range increased (Fig. 6 $\mathrm{G}-\mathrm{I})$. The mean dynamic range was $14 \mathrm{CL}$ in the control group $(n=7)$ and $18 \mathrm{CL}$ in the Contour group $(n=3)$.

Postoperative speech discrimination scores for the Contour patients for CID sentence scores, in quiet, are shown in Table 2, and range from $70 \%$ (patient 1) to $100 \%$ (patients 2 and 3).

\section{DISCUSSION}

A perimodiolar electrode array suitable for general clinical use should curl optimally within the cochlea to achieve a position close to, but not touching, the modiolus. It should not induce more insertion damage than the design it replaces. Earlier studies in this laboratory showed that designs that curl satisfactorily in acrylic models of the cochlea do not necessarily achieve similar shape performance in preserved human temporal bones. Furthermore, a particular design that achieved a perimodiolar position through use of a positioner pushing against the outer wall of the otic capsule to force the electrode medially was found to cause extensive damage to cochlear structures $(3,12)$. After those investigations, we favored a passive positioning system, which relies on the recoil properties of the precurved electrode array only to find its final position. However, another active mechanical positioning system to bring the electrode closer to the modiolus is currently used by the HiFocus electrode (Advanced Bionics Company, Sylmar, CA, USA). This modiolus-hugging electrode design (16) uses a wedge-shaped silicone positioner, which is introduced laterally to the electrode during implantation and positions the array close to the modiolus. In a recent temporal bone insertion study, Fayad et al. (17) reported no damage to the osseous spiral lamina in all 10 temporal bones studied.

The observations made during the preliminary insertions of the Contour array, using surface preparation temporal bones, suggested that a cochleostomy allowing both the basilar membrane and the modiolus to be viewed by the surgeon optimized conditions for a successful and atraumatic insertion of the Contour electrode array. The position of the cochleostomy ensures that entry occurs only into the scala tympani. In addition, a cochleostomy of $1.5 \mathrm{~mm}$ to $2.0 \mathrm{~mm}$ does not constrain the direction of the initial movement of the electrode array, thus allowing it to better follow the geometry of the scala tympani in the lower basal turn.

Statistical comparison showed that the probability of basilar membrane penetration for temporal bones implanted with the Contour electrode array was equivalent to that reported in an earlier study of prototype straight arrays (1). Where the basilar membrane was penetrated, it occurred close to the junction of the basilar membrane with the spiral ligament. However, the adjoining osseous spiral lamina appeared to have been left intact. This suggests that the recoil properties of the Contour electrode array are insufficient to cause damage to the brittle os- 
seous spiral lamina medial to the perforation. Moreover, it suggests that if the electrode array is not manipulated further after full insertion, the possibility of damage to these structures can be avoided.

The surface preparation method used to evaluate the insertion trauma allows assessment of the intracochlear position of the electrode array and the detection of any gross damage to the basilar membrane. 1t has been shown previously in animal studies that this kind of damage results in severe local neural degeneration $(7-10)$. However, the periendolymphatic fistula associated with piercing of the basilar membrane can be overgrown by endogenous fibrous tissue, as was observed by Johnson et al. (18) in a patient who received bilateral implants. Although the actual area of damage to the basilar membrane appeared to be restricted to the area of penetration in the two temporal bones showing damage in study 1 , the resting position of the electrode array on top of the basilar membrane apical to the perforation would have caused more widespread damage to the organ of Corti and Reissner's membrane. Studies in cats, in which the electrode array was purposely positioned on top of the basilar membrane along the scala vestibuli, have reported perforation of Reissner's membrane that resulted in a localized loss of spiral ganglion cells (9). However, in the case of minor damage to cochlear structures in a living subject, such as tears in the spiral ligament, only localized fibrotic reaction might result (18), especially if both the osseous spiral lamina and the basilar membrane are left intact.

Image analysis of the radiographs of the three patients showed that the Contour electrode array was positioned close to the modiolus, although not necessarily uniformly along the entire array for each patient (Fig. $5 \mathrm{D}-\mathrm{F}$ ). A potential solution to the variability in position could be to increase the recurling properties of the electrode array that position it against the modiolar wall. However, the present design uses a minimum restoring force because of a concern that damage from force applied to the modiolar wall could lead to consequent degeneration of spiral ganglion cells.

It has been previously reported that the electrode impedance increased when an electrode array was moved close to the modiolus (19). This is most likely caused by a change in current flow as the distance between the stimulating electrode and the medial wall of the scala tympani changes. This immediate rise in electrode impedance after positioning appears to be different from the slower rise caused by the formation of a fibrous tissue sheath around the electrode postoperatively. The clinical importance of higher impedance values in perimodiolar electrode arrays has not yet been fully determined; however, previous studies $(6,19)$ suggested that evoked auditory brainstem response or stapedius reflex thresholds were generally lower when the electrode array was in a perimodiolar position. Impedance measurements in the current study were performed to monitor impedance values longitudinally, but also to investigate whether impedance differences between electrodes could be de- tected and correlated with the estimation of electrode position derived from image analysis.

The impedance values of patients 1 and 2 appeared to vary with the estimated radial distance of the electrodes from the modiolus (Fig. $6 \mathrm{D}, \mathrm{E}$ ). The results suggest a negative correlation of the area-corrected impedance values with the estimated radial distance of the electrodes to the modiolus (Fig. 6 D,E), indicating that electrode impedance did increase with improved modiolar proximity of the electrode array. The impedance values recorded from patient 3 are similar to those of the control group, presumably reflecting the consistency of electrode distance from the modiolus (Fig. 6 F).

The $\mathrm{T}$ and $\mathrm{C}$ levels suggested a positive correlation with the estimated radial distance of the electrodes from the modiolus. The $\mathrm{T}$ and $\mathrm{C}$ levels of electrodes positioned close to the modiolus were, in general, lower than those of electrodes positioned farther away (Fig. $6 \mathrm{G}-\mathrm{I}$ ). Compared with the mean $\mathrm{T}$ and $\mathrm{C}$ levels of the control patients, the $\mathrm{T}$ and $\mathrm{C}$ levels of the Contour patients were lower for electrodes that were positioned very close to the modiolus, and within the same range for electrodes positioned more laterally (Fig. $6 \mathrm{G}-\mathrm{I}$ ). These data are consistent with the findings of Shepherd et al. (6), who reported significant reductions of the evoked auditory brainstem response thresholds in cats when an intracochlear electrode array was moved from the outer wall of the scala tympani toward the modiolus.

The progressive decrease in the mean $\mathrm{T}$ and $\mathrm{C}$ levels, as well as the slight increase in the dynamic range from the base to the apex in the control group (Fig. $6 \mathrm{G}-\mathrm{I}$ ) could be associated with the gradual reduction in width of the scala tympani beyond the first $1.5 \mathrm{~mm}$ from the round window (20). This would have the effect of positioning the standard straight array slightly closer to the modiolus in the upper basal turn and beyond. The effect on both $\mathrm{T}$ and $\mathrm{C}$ levels appears to be quite large, given the anticipated small change in electrode position, and may be a factor in subject selection for the control group.

On closer examination, the impedances and $\mathrm{T}$ and $\mathrm{C}$ levels for electrodes 9 through 14 for patient 1 seemed less well correlated with the estimated radial distance of the electrodes from the modiolus than was the case for patient 2 (Fig. 6 D,E). In patient 1 , the Contour electrode array appeared to be positioned very close to the lateral wall of the otic capsule at the first bend of the scala tympani. Moreover, its trajectory as projected by the image analysis was similar to the trajectory shown by the two electrode arrays in study 1 , which were found to have penetrated the basilar membrane (Fig. 5 C,D). These combined findings suggest that the electrode array in patient 1 may have penetrated the basilar membrane. It should be noted that patient 1 showed speech perception scores of $70 \%$ on open-set sentence test material, less than that reported for patients 2 and 3 .

In conclusion, the results of temporal bone studies suggest that insertion of the Contour electrode array can be achieved without an increase in the incidence of basilar membrane perforation, in comparison with the 
straight array. A specific surgical technique is recommended, and training of the implanting surgeons in the use of the new device would be important. The $1.5-\mathrm{mm}$ to 2-mm cochleostomy suggested is larger than the standard Melbourne practice for the Nucleus device, which potentially increases the risk of ascending labyrinthitis. However, a cochleostomy larger than the suggested 2 $\mathrm{mm}$ is routinely used by surgeons implanting other commercial cochlear implant arrays. The Contour array was inserted more deeply and positioned closer to the modiolus in all patients in comparison with the standard Nucleus straight array. However, in two cases, the position was not uniform for the entire length of the array. Initial speech perception data show that all three patients gained useful open-set speech perception from their devices.

Future work in this center will assess the interaction between electrode position, function, and patient performance for these and additional patients using the Contour electrode array.

Acknowledgment: These studies were conducted under the approval of the Royal Victorian Eye and Ear Hospital (RVEEH) Human Research Ethics Committee (Perimodiolar Electrode Array, Human Temporal Bone Study, No. 96/303H, and Evaluation of Perimodiolar Electrode Arrays, No. 96/307). The Contour electrode array used in these studies has been developed by Cochlear Limited in collaboration with the Cooperative Research Centre. The authors are grateful in particular to John Parker, Ian Darley, and Fysh Dadd of Cochlear Limited for their work in the electrode design and development. They also thank Dr. Markus Dahm and Mr. Brian Pyman for suggestions and supporting work in the initial electrode insertion studies; Dr. Jin Xu, CRC, and Jennifer Kaye of the RVEEH for taking the radiographs, and David Lawrence of the Bionic Ear Institute for help with the photographs.

\section{REFERENCES}

1. Shepherd RK, Clark GM, Pyman BC, et al. Banded intracochlear electrode array: evaluation of insertion trauma in human temporal bones. Ann Otol Rhinol Laryngol 1985;94:55-9.

2. Cohen LT, Xu J, Xu S-A, et al. Improved and simplified methods for specifying positions of the electrode bands of a cochlear implant array. Am J Otol 1996;17:859-65.

3. Tykocinski M, Cohen LT, Pyman BC, et al, Comparison of electrode position in the human cochlea using various peri-modiolar electrode arrays. Am J Otol 2000;21:205-11.
4. Rebscher S. Heilmann M, Bruszewski W, et al. Strategies to improve electrode positioning and safety in cochlear implants. IEEE Trans Biomed Eng 1999;46:340-52.

5. Smith DW, Finley CC, v.d. Honert $\mathrm{C}$, et al. Behavioural and electrophysiological responses to electrical stimulation in the cat: 1 . Absolute thresholds. Hear Res 1994;81:1-10.

6. Shepherd RK, Hatsushika S, Clark GM. Electrical stimulation of the auditory nerve: the effect of electrode position on neural excitation. Hear Res 1993;66:108-22.

7. Shepherd RK, Clark GM, Black RC. Chronic electrical stimulation of auditory nerve in cats: physiological and histopathologic results. Acta Otolaryngol (Stockh) 1983:(suppl399):19-31.

8. Sutton D, Miller JM, Pfingst BE. Comparison of cochlear histopathology following two implant designs for use in scala tympani. Ann Otol Rhinol Laryngol 1980:89(Suppl2,Pt 2);11-4.

9. Clark GM. An evaluation of per-scalar cochlear electrode implantation techniques: an histopathologic study in cats. $J$ Laryngol Otol 1977:91:185-99.

10. Leake PA, Snyder RL, Hradek GT, et al. Factors affecting survival and functional status of spiral ganglion neurons in deafened cats. Proceedings of the 1999 conference on implantable auditory pros. theses. $1999: 18$

11. Gestoettner W, Franz P, Hamzavi J, et al. Intracochlear position of cochlear implant electrodes. Acta Otolaryngol (Stockh) 1999;119: 229-33.

12. Richter, B, Jaekel K, Kuzma J et al. Alteration of fine cochlear structures after implantation of a new perimodiolar electrode array prototype. Eur Arch Otol Rhinol Laryngol 1998;255:92.

13. Treaba C, Xu J, Xu S-A, et al. Pre-curved electrode array and insertion tool. Ann Otol Rhinol Laryngol 1995;104(Suppll66): $438-41$.

14. Tykocinski M, Cohen TC, Saunders $E$, ef al. Insertion study using new peri-modiolar electrode array designs. Proceedings of the 1999 conference on implantable auditory prosiheses, 1999:72.

15. Xu J, Xu S-A, Cohen LT, et al. Cochlear view: postoperative radiography for cochlear implantation. Am J Otol 2000;21:49-56.

16. Kuzma JA, Balkany TI. New generation Clarion electrodes for highly focused stimulation. Proceedings of the 1999 conference on implantable anditory prostheses, 1999:60.

17. Fayad JN, Luxford W, Linthicum FH. The Clarion electrode positioner: temporal bone studies. Am J Otol 2000,21:226-9.

18. Johnson LG, House WF, Linthicum FH. Otopathologic findings in a patient with bilateral cochlear implants. Ann Otol Rhinol Laryn" gol 1982;91(Suppl91):74-89.

19. Battmer R, Kuzma J, Frohne C, et al. Better modiolus hugging electrode placement: electrophysiological and clinical result of new Clarion electrode positioner. Proceedings of the 4th European symposium on pediatric cochlear inplantation, 1998:18.

20. Hatsushika S, Shepherd RK, Tong YC, et al. Dimensions of the scala tympani in the human and cat with reference to cochlear implants. Ann Otol Rhinol Laryngol 1990;99:871-6. 


\section{University Library}

\section{- M M N E R VA A gateway to Melbourne's research publications}

Minerva Access is the Institutional Repository of The University of Melbourne

Author/s:

Tykocinski, M;Saunders, E;Cohen, LT;Treaba, C;Briggs, RJS;Gibson, P;Clark, GM;Cowan, RSC

Title:

The Contour electrode array: Safety study and initial patient trials of a new perimodiolar design

Date:

2001-01-01

Citation:

Tykocinski, M., Saunders, E., Cohen, L. T., Treaba, C., Briggs, R. J. S., Gibson, P., Clark, G. M. \& Cowan, R. S. C. (2001). The Contour electrode array: Safety study and initial patient trials of a new perimodiolar design. OTOLOGY \& NEUROTOLOGY, 22 (1), pp.33-41. https:// doi.org/10.1097/00129492-200101000-00007.

Persistent Link:

http://hdl.handle.net/11343/27591 